\title{
The Psychological Contract: The Changing Nature of Employee-Employer Expectations
}

\author{
Ms. Indu Bala \\ Assistant Professor \\ GGS College of Management \& Technology, Gidderbaha
}

\begin{abstract}
The psychological contract describes a phenomenon that occurs largely in the minds of employers and employees. The term governs all the ideas and expectations that workers have about their jobs and includes beliefs about their roles and responsibilities as employees. One of the fundamental challenges for $\mathrm{HR}$ is to help management maintain the appropriate balance between the realities of the business model and the needs of our employees. Success comes when the balance exists and is understood (Kevin Sullivan Former VP of HR). There is a great challenge for a business today- a basic shift in employment expectations both from the employee's and the company perspectives. Both the right person and the right job are being affected by changing values. This research paper tries to find out the expectations of employers and employees in the present era . A detailed overview of any organization has been undertaken. Various ways have been suggested to deal with situation and emotions when expectations are not being met.
\end{abstract}

Keyword: Expectations, Management, Employees

\section{OBJECTIVES}

1.) To understand the changing nature of employee- employer expectations.

2.) To study an organization highlighting changing nature of employee- employer expectations.

3.) To suggest ways of dealing with situations and emotions when expectations are not being met.

\section{INTRODUCTION}

A psychological contract represents the mutual beliefs, perceptions and informal obligations between an employer and an employee. It sets the dynamics for the relationship and defines the detailed practicality of the work to be done. It is distinguishable from the formal written contract of employment which for the most part only identifies mutual duties and responsibilities in a generalized form.

The psychological contract includes the expectations of the employees from their job and includes the beliefs about their behaviour and duties as employees. Psychological contract is of implicit nature in which expectations from both sides and a certain level of understanding and trust becomes a part of the agreement between employee and employer. It is seen that employees often expect to be fairly treated and compensated for the work they perform within a given company. On the other hand employers too often aware that the compensation they offer is expected to match the efforts made by the workers in their work. If we consider from the point of view of employers, they expected that all the employees to do best job they can and to show their capacity to adequantly handle the situations according to their position they hold within the company.

We can say that psychological contract is a dynamic and seemingly living entity. The level of understanding between both the parties refine from the extent of the fulfillment of expectations on both sides. The psychological contract started to begin with many questions that arises in the minds of virtually all employees. These questions involves the concern that how much they are expected to contribute to particular company and in return what will they receive. The answers to such questions create the level of understanding 
between employees and employers and that is the base of the psychological contract.

In psychological terms issues as to whether promises and expectations have been kept and met and whether the resulting arrangements are fair are fundamental to the trust between the employee and the employer. The first year of employment is critical as actual performance by the employee can be measured against claims and promises made during the interview and the management has began to establish a track record in its relationship with the employee at supervisor and manager level.

The reality of employment rights and duties emerges through the interpersonal relationships formed in the workplace. How employers, supervisors and managers behave on a day-to-day basis is not determined by the legal contract. Employees slowly negotiate what they must do to satisfy their side of the bargain and what they can expect in return. This negotiation is sometimes explicit example in appraisal or performance review sessions but it more often takes the form of behavioral action and reaction through which the parties explore and draw the boundaries of mutual expectation. Hence the psychological contract determines what the parties will or will not do and how it will be done. When the party's expectations match each other, performance is likely to be good and satisfaction levels will be high.

\section{RESEARCH METHODOLOGY}

The study is based on the secondary data. Information has been collected from Internet, newspaper, existing literature, magazines etc.

\section{THE NATURE OF EMPLOYER/EMPLOYEE EXPECTATIONS}

There is a great challenge for the business in the present era. Expectations shift both from the employee's and company's perspectives. Let us study it in detail.
Demands get changed: Today employers are looking for different things from their work life than they were a decade ago. Employees having busy schedule, sixty hour work in a week, weekend training, daily meetings demands balance in relation to family life, community commitment and recreation. Today, employees look for benefits such as assistance programs, family leave, flexible hours, easy promotion and financial assistance programs. As commercial organizations grew in size and complexity, societies have developed expectations of a better work life balance, reinforced by legislation.

Employers expectations have also changed. Employment demands for creative thinkers with better experience. The work force is required to be more flexible to meet new challenges quickly and effectively. Employees are expected to do each and every work at all level.

Motivation and commitment should need to be enhanced. Transfers and promotions is to be follow the agreed path in a timely fashion. Reward systems must adapt to new emphasis to knowledge.

Ability and Knowledge both contribute: Wages and salary both are very important to identify the employee value in the company. Compensation paid to an employee decides their demand in the Company. However it is based on an employee's knowledge, ability to do a task as well as the capacity to shift from one job to another. Now experience is only appreciated if it is a result of good contribution.

Companies have diverted their focus on team reward, profit sharing and bonuses are paid taking into consideration that collective effort gives the best result. Nowadays the employee behavior to impress their boss is not at all appreciated. Knowledge based employment is the only fact which is highly considered. Team Work is highly recommended and mentioned in job descriptions, and it is taken as important base for evaluation of an employee task.

HR Function: According to human resources views, the work is very complex. Compensation and benefits have to be under constant check . Pay and benefits should be according to the changing expectations of the employees. The company should offer incentives for innovative workers. 
HR department is under an obligation to change its function according to shifting values. There is a great challenge for an applicant to sell a prospective employer on their skills and talents. On the other hand company is under the same obligation to sell its culture and vision to job applicants. Interview process is often declared as a team decision but few hiring decisions are under with one supervisor or manager.

Managers and supervisors needs training and resoures to deal with changing working environment. As the workforce values are changing, Interpersonal, behavioural skills, workshop, communication techniques and seminars are increasingly offered to suit the business practice.

Today's Organization: In today world, organization that is likely to be very different due to competitive pressures and technological breakthroughs. Organizations today are

- leaner and more agile

- more focused to identify value from the customer point

- more focus on dynamic competitive requirements and strategy

- less hierarchical in structure and decision authority

- less likely to provide lifelong careers

- continually reorganizing to gain competitive advantage

\section{OVERALL CHANGES IN AN ORGANIZATION ENVIRONMENT}

- Reduced hierarchical level: Hierarchies are complicated and it cannot respond quickly to changing market demands and to do continuous innovation. Hierarchies are being replaced by cross unit organizational groupings with fewer layers and increase decentralized decision making.

- Gap Between boundaries increases: As organizations become more laterally structured, gap between boundaries begin to increase as different parts of the organization need to work more effectively together. Boundaries between departments as well as between job categories (manager, professional, technical) become looser and there is a greater need for communication and knowledge sharing.

- Team based organization structure: The move toward a team based organizational structure results from pressures to make decisions in very less time, to reduce inefficiencies, and to continually improve work processes.

- Management loose command: Workers are no longer wanted to comply with rules and orders, but rather to be committed to organizational goals and mission. Employees gain more decision authority and work; managers become more social supporters and guides rather than commanders.

- Continuous change: Organizations are expected to continue the cycles of reorganization. However these changes may be both large and small. Kling and Zmuidzinas identify three types of change metamorphosis (far reaching, fundamental change), migration (shifts toward a new form), and elaboration (changes that enhance some aspect of work).

Changing work context come with the new psychological contract: As work changes, the nature of the relationships between employees and employers has also get change. In the new work context, the informal psychological contract between workers and employers, what each expects of the other focuses on competency development, continuous training, and work life balance. In contrast, the old psychological contract was all about job security and steady advancement within the firm. Even few workers expect or desire lifelong employment in a single firm.

Changing work context comes with following differences:

- Corporate indifference : In particular working environment individual desire participation, expression, identity, and quality of life. All these values which are needed to be their for an organizations, but largely ignored in practice as organizations 
continue to focus on reducing fixed labor costs.

- Reduced loyalty and commitment: With little expectation for advancement, workers are less committed to organizational goals rather they try to more commit to their own learning and development. As the knowledge and technological skills that employees bring with them to the workplace are transportable and are not lost when a new job is taken.

- Increased time burdens: Years of downsizing and outsourcing have produced the feeling of having too much to do and too little time to do it. In order to keep up with workloads, many workers are spending longer hours at work, according to reports by the Bureau of Labor Statistics and the Center for Workforce Development.

- Flexible work arrangements do not keep up with employee preferences. The Work trends 2000 report found that $74 \%$ of workers were not allowed flexible hours and work arrangements (such as telecommuting). Those with flex hours have limited freedom regarding when and where to work. The vast majority of workers have to commit to a specific day to work at home or a specific day to take off if they work four10-hour days.

Cognitive Workers: Cognitive workers are expected to be more functionally able to work across many kinds of tasks and situations. The broader span of work brought about by changes in organizational structure, also creates new demands including:

- Increased complexity of work: Workers need to know more not only to do their jobs and but also to work effectively with others on teams. Many tasks require great knowledge and judgment skills to carry out work that is more novel, extemporaneous, and context based with few rules and structured ways of working. Although demand for high cognitive skills are especially prominent in professional and technical jobs even administrative tasks require more independent decision making and operational decision making.

- Continuous competency development: Not only do workers need to keep their technology skills up to date they need to be continuous learners in their knowledge fields. Time to read and attend training classes is a perquisite for all workers.

- Different ways of thinking: Rosabeth Kantor argues that cross-functional and cross boundary teams require kaleidoscope thinking, the ability to see alternative perspectives and to create new patterns of thinking that propel innovation. Workers also need to be able to synthesize different ideas in order to make the cognitive leaps that underlie innovation.

\section{Example}

One of the example we can take during the apple critical time, there arises an urgent need for some dialogue with employees about their expectations of the company, their questions and possible misunderstanding due to the different changes in an organization. Many employees try to find out their position again and again with the commitment to apple. On the other hand many of the employees were not able to understand their role in particular organization. Therefore HR felt that there is a great need to acknowledge the employees realities of the Apple of yesterday and Apple of today .

Organizational chart of apple Inc. is very large and shows all the important functions. But it is not much descriptive. More descriptive will be choosing only the main functions of the company which affect the organizational structure of the all product lines.

The main areas of Apple's management

- Marketing

Marketing makes up the basic part. The goal of this part of the firm is to identify the customer's needs and the products that satisfy them.

- $\quad$ iPhone Software

It seems that the iPhone is such important product for Apple that needs its own department for managing the software what iPhone comes with. Furthermore very 
similar software is used in iPad the new Apple's device.

- General Counsel

General Counsel helps to coordinate all Apple organizational departments in order to work perfectly and effectively.

- Industrial Design

Industrial Design is responsible for crafting the appearance of all Apple products including the Apple Macintosh computer line.

- Device Engineering

Device Engineering solves all the problems that relates to all Apple production lines except the design of the products. Production tasks, hardware and software skills. Apple design is managed by another department.

- $\quad$ Retail

The main task of this unit is to maintain all the business channels that Apple uses including Apple Store or iTunes.

- Software Engineering

Is responsible mainly for developing of the operational system OS $\mathrm{X}$ and then also about others Apple's software products like iWork, etc.

From the very beginning (year 1977) the company Apple had very simple organizational structure which was created only by Steven Jobs and Stephen Wozniak. But the same year was hired first professional manager A.C. Markkula. As the enterprise was growing there came more complicated structure.

HR involves a wide range of activities and issues, with responsibility for their enactment with different people. Let us study some key role of HR guided by basic assumptions as follows:

- Main focus of the HR activity is that of achieving high performance by developing the skills and knowledge of staff and aligning staff developments to the needs of the organization.

- The key levels of HR (selection, communication, training, reward, and development) should be used to gain employee commitment to the organization and its goals and not just compliance with them.

- Individual employees are responsible for achieving their goals.

- HR must provide superior quality products and services that support Apple's position.

- HR must establish different norms for evaluating its effectiveness.

- The evaluation process of HR should be impartial and independent from the process concerned with policy making, and the delivery and management of development assistance.

- Management must provide a basis for accountability, including the provision of information to the employees.

\section{DIFFERENT APPROACHES TAKEN TO IMPLEMENT CHANGES}

As the company has grown and been led by a series of chief executives, each with his own idea of what Apple should be, some of its original character has arguably been lost, but Apple still has a reputation for fostering individuality and excellence that reliably draws talented people into its employ. This was especially after Jobs' return. To recognize the best of its employees, Apple created the Apple Fellows program, awarding individuals who made extraordinary technical or leadership contributions to personal computing while at the company.

Apple is also known for strictly enforcing accountability. Each project has a "directly responsible individual," or "DRI" in Apple jargon . As an example, when iOS senior vice president Scott Forstall refused to sign Apple's official apology for numerous errors in the redesigned Maps app, he was forced to resign Numerous employees of Apple have cited that projects without Jobs' involvement often take longer than projects with his involvement.

At Apple, employees are specialists who are not exposed to functions outside their area of expertise. Jobs saw this as a means of having best- 
in-class employees in every role. For instance, Ron Johnson who was Senior Vice President of Retail Operations until November 1, 2011, was responsible for site selection, in-store service, and store layout, yet he had no control of the inventory in his stores (which is done companywide by then$\mathrm{COO}$ and now CEO Tim Cook who has a background in supply-chain management). This is the opposite of General Electric's corporate culture which has created well-rounded managers.

Under the leadership of Tim Cook who joined the company in 1998 and ascended to his present position as CEO, Apple has developed an extremely efficient and effective supply chain which has been ranked as the world's best for the four years 2007-2010. The company's manufacturing, procurement and logistics enables it to execute massive product launches without having to maintain large, profit-sapping inventories; Apple's profit margins have been 40 percent compared with 10-20 percent for most other hardware companies in 2011. Cook's catchphrase to describe his focus on the company's operational edge is "Nobody wants to buy sour milk". The company previously advertised its products as being made in America up to the late 1990s, however as a result of outsourcing initiatives in the 2000s almost all of its manufacturing is now done abroad. According to a report by the New York Times, Apple insiders "believe the vast scale of overseas factories as well as the flexibility, diligence and industrial skills of foreign workers have so outpaced their American counterparts that "Made in the U.S.A." is no longer a viable option for most Apple products."

Unlike other major US companies, Apple has a relatively simple compensation policy for executives, which does not include perks that other CEOs enjoy such as country club fees and private use of company aircraft. The company usually grants stock options to executives every other year.

\section{UPLIFTMENT FOR THE LABOURER}

In 2006, one mail reported on the working conditions that existed at factories in China where the contract manufacturers Foxconn and Inventec produced the iPod. The article stated that one complex of factories that assembles the iPod (among other items) had over 200,000 workers that lived and worked in the factory, with employees regularly working more than 60 hours per week. The article also reported that workers made around $\$ 100$ per month and were required to live pay for rent and food from the company, which generally amounted to a little over half of workers' earnings. Apple immediately launched an investigation and worked with their manufacturers to ensure acceptable working conditions. In 2007, Apple started yearly audits of all its suppliers regarding worker's rights, slowly raising standards and pruning suppliers that did not comply. Yearly progress reports have been published since 2008. In 2010, workers in China planned to sue iPhone contractors over poisoning by a cleaner used to clean LCD screens. One worker claimed that he and his coworkers had not been informed of possible occupational illnesses. After a spate of suicides in a Foxconn facility in China making iPads and iPhones, albeit at a lower rate than in China as a whole workers were forced to sign a legally binding document guaranteeing that they would not kill themselves. In 2011 Apple admitted that its suppliers' child labor practices in China had worsened. Workers in factories producing Apple products have also been exposed to nhexane, a neurotoxin that is a cheaper alternative than alcohol for cleaning the products.

\section{ORGANIZATION CULTURAL ASPECTS AND ITS TECHNOLOGY}

Apple was one of several highly successful companies founded in the 1970s that bucked the traditional notions of what a corporate culture should look like in organizational hierarchy (flat versus tall, casual versus formal attire, etc. Originally, the company stood in opposition to staid competitors like IBM by default, thanks to the influence of its founders; Steve Jobs often walked around the office barefoot even after Apple was a Fortune 500 company. By the time of the "1984" TV ad, this trait had become a key way 
the company attempted to differentiate itself from its competitors. According to a 2011 report in Fortune, this has resulted in a corporate culture more akin to a startup rather than a multinational corporation.

Apple has created technology-based tools to enhance employee and management selfsufficiency providing information on demand. Using technology HR has transformed routine but critical work by reducing clerical expense.

Employee Help Center is staffed by a small group of who are well-trained in Apple policies and procedures. On-line Internet support is also available. More complex questions and issues are routed to a support group of senior HR staff. More serious issues may require a face-toface investigation. HR is using technology to get out of the transaction business and focus on building line accountability for people management. HR is using the desktop technology to transfer all traditional personnel administration and documentation requirements to the line businesses. Today It's HR system is almost paperless. On-line applications have been built to handle almost all of the manager employee transactions, regarding compensation changes, promotions and demotions and performance reviews, adding someone to the payroll. All policies and procedures are available on-line. This dramatic change greatly affected how HR viewed its role and power within the organization. In the starting biggest resistance to the changes was from the senior HR professionals. Today resistance is much lower because the clients have accepted the new systems model enthusiastically. HR has redefined the way work will be done and given it back to management better packaged and more efficient.

\section{OVERALL IMPACT OF BEST PRACTICE}

A change that Apple's HR community implemented takes time to be successful. The results, however more than compensate the implemented task. At Apple shift has resulted in increased HR access and support for the manager and employees, in an order of magnitude greater than in the past. The quality of the interaction between management and employees has improved. This shift has put HR into a position to contribute value-added support to the business transformation of the company, all while running its business model with real efficiency and innovative thinking. Apple's HR is the model for other support functions to emulate. Apple has been one of the world's largest technology companies by revenue. It is the world's thirdlargest mobile phone maker after Samsung and Nokia. Fortune magazine named Apple the most admired company in the United States in 2008, and in the world from 2008 to 2012. However, the company has received criticism for its contractors' labor practices, and for Apple's own environmental and business practices. As of November 2012, Apple has 394 retail stores in fourteen countries as well as the online Apple Store and iTunes Store It is the largest publicly traded corporation in the world by market capitalization, with an estimated value of US\$626 billion as of September 2012.The Apple market cap is larger than that of Google and Microsoft combined. As of September 29, 2012, the company had 72,800 permanent full-time employees and 3,300 temporary full-time employees worldwide. Its worldwide annual revenue in 2010 totaled $\$ 65$ billion, growing to \$156 billion in 2012.

\section{TO DEAL SITUATIONS EMOTIONS EXPECTATIONS NOT BEING MET \\ WITH AND WHEN ARE}

There have been large number of surveys, studies, books and articles written by human resource professionals that have concluded employee satisfaction and employer expectations share more similarities than differences. The balance lies in listening to one another concerns and proceeding collaboratively.

To achieve success, it is critical for organizations to do the following:

- Define the desired employment deal as it relates to the company strategy and workforce needs. 
- Ensure the right decision and balance of different reward programs considering constraints on rewards.

- Understand employee preferences for rewards s special preference among top performing, high potential and critical skill employees and should be prepared to adjust the reward plans accordingly.

- Understand the impact of demographics on employee preferences not only for monetary rewards such as compensation and other benefits but for environmental concerns such as work/ life balance.

- Use the results of workforce undertakings to understand the projected work done by the workforce and to align the employment deal/total rewards accordingly.

- Develop a total rewards philosophy reflecting the desired deal and clearly linked to business objectives.

- Ensure pay differentiation for top performing employees across all tasks.

- Develop consistent messages about the employment work and total rewards philosophy.

- Communicate messages frequently through the Whole Organization, localized and manager based channels to create alignment between employer and employee expectations.

\section{Steps to Create Co-operative Environment}

- Support managers in their role by providing Frequent training on effective goal setting, performance measurement, and making compensation decisions.

- Take steps to increase line of sight for employees into performance goals, contents and results.

- Ensure that communication between managers and employees increase understanding of performance expectations and compensation decisions.

- Improve the communication skills by adapting public speaking techniques to your company message. Employees will respond to and incorporate your expectations better if the message is deliver them in a concise and engaging manner.

- Don't limit the communication regarding expectations to personnel assessment time. Take the time to discuss the expectations with staff on a regular and frequent basis, outside of regularly scheduled reviews.

- Create an environment in which questions are welcomed. Effort should strive to create an atmosphere in which employees feel they can ask you for clarification on what is expected of them.

- $\quad$ Try to Motivate an employee by defining the expectations. Having strong communication and clear direction will help employees understand exactly what organization aim to accomplish.

Employee's responsibility for an organization

- Every Employee should make sure whether they have mastered the skills required to perform the work completely. If they are not sure about how to handle the work allotted to them they should talk with their superiors and get suggestions and directions in fulfilling the work allotted to them.

- The employees should have sense of responsibility towards the resources of the Organization. As a part of the Organization every employee is equally responsible to ensure that each resource is used properly and in an efficient way .

- It is the prior responsibility of every employee to listen carefully and take initiative to know more about the new work assigned to them. This will help the employees to learn new skills and to attain the organization goal in an efficient way.

- Employee should try to be punctual and to do the assigned task without any delay.

- Employee should ensure that they have good participation in team work so that it will help to create unity to attain the common goals of the organization.

- The employee should consider in their own development include keen to have a variety of assignments, handling tough problems and asking for feedback. 
- $\quad$ Every employee should be keen to have a systematic diagnosis of the current situation in order to determine both the need for change and the capability to change.

- Every employee should cooperate with the organization by providing relevant and appropriate information to support the system.

\section{CONCLUSION}

Effective communication can provide a friendly atmosphere where employees are comfortable and can focus on doing what they do best. Prior generations had been happy to have a job to support the family. The employer was considered concerned if the workplace provided a reasonable expectation of job security, a living wage, opportunity for over time, adequate working conditions, personal loyalty to workers, vacation and some benefits. The employer was perceived to have the upper hand in decision making for the company. A psychological contract represents the mutual beliefs, perceptions, and informal obligations between an employer and an employee. It sets the dynamics for the relationship and defines the detailed practicality of the work to be done. It is distinguishable from the formal written contract of employment which for the most part only identifies mutual duties and responsibilities in a generalized form. Even though the expectations are not categorized in order, it is important to note that money is not the top expectation for either employee or employer. When the parties expectations match each other, performance is likely to be good and satisfaction levels will be high So long as the values and loyalty persist, trust and commitment will be maintained. But a negative psychological contract can result in employees becoming disenchanted, de-motivated and resentful of authoritarianism within the organisation. This will result in an increasingly inefficient workforce whose objectives no longer correspond to the organisation they work for.

In a long-term relationship there is a need of adjustment and accommodation. Such adjustment and accommodation sometimes be a difficult and stressful process. There is a greater demand for an employee to do an adjustment in an organization. Employees have moral duties to the organization, co-workers, and customers. The employee must recognize that certain personal values may be achieved only by working successfully toward organizational goals. In this sense employment is a means to an end and a greater degree of overlap between his/her desired ends and those of the employer facilitates the achievement of both. It is then in one's own best interest to seek employment in an organization that most nearly reflects one's personal values and goals. To this end then the employee must have a realistic grasp of one's own characteristics and preferences.

\section{REFERENCES}

[1] Conway, Neil \& Briner, Rob B. Understanding Psychological Contracts at Work: A Critical Evaluation of Theory and Research. Oxford, UK: Oxford University Press, (2005)

[2] Rousseau, Denise M. Psychological Contracts in Organizations: Understanding Written and Unwritten Agreements. Thousand Oaks, CA: Sage, (1995)

[3] Boddy, John. "Negotiating the 'psychological contract'". Training Journal, Aug 2000: 10. Jenna Pickup

[4] Rousseau, D. M. (2011). The individualorganization relationship: The psychological contract. In S. Zedeck (Ed.), APA handbook of industrial and organizational psychology (pp. 191-220). Washington, DC: American Psychological association.

[5] Rousseau, D. M. (1995). Psychological contract in organizations: Understanding written and unwritten agreement. Newbury Park, CA: Sage.

[6] Emerson, R (1981). Social Exchange Theory. in M. Rosenberg, \& R. Turner (Eds), Social Psychology: Sociological Perspectives (pp. 30-65). New York: Basic Books.

[7] Burack, E (1993). Corporate resurgence and the new employment relationships. New York: Quorum Press 